\title{
MODIFIKASI PATI DARI BUAH PISANG TALAS SEBAGAI EKSIPIEN \\ TABLET DENGAN TEKNIK PEMANASAN DALAM BERBAGAI TEMPERATUR
}

\author{
Hariati, Mirhansyah Ardana, Laode Rijai \\ Laboratorium Penelitian dan Pengembangan Kefarmasian "Farmaka Tropis" \\ Fakultas Farmasi, Universitas Mulawarman, Samarinda, Kalimantan Timur \\ Email: hariati356@gmail.com
}

\begin{abstract}
Modification starch pregelatinized of Musa paradisiaca var Sapientum L has been performed by heating starch at its gelatinization temperature. The study begun with determining the exact pregelatinized temperature and comparing the physical and mechanical characteristics of starch sample. The data obtained shows the percentage of modified starch is $90,12 \%$ in $60,41^{\circ} \mathrm{C}$. The data obtained from characteristics study shows pregelatinized starch samples has bigger particle size than the usual starch sample. Fluidity evaluation shows pregelatinized starch sample has a better performance, which is $9,7 \mathrm{~g} / \mathrm{sec}$ and $23,56^{\circ}$ of resting point.
\end{abstract}

Keywords: Musa paradisiaca var Sapientum L, starch pregelatinized, tablet excipient, disintegrant

\begin{abstract}
ABSTRAK
Modifikasi pati pisang talas pregelatinasi telah dilakukan dengan memanaskan pati pada suhu gelatinisasinya. Penelitian diawali dengan menentukan suhu pregelatinasi yang tepat dan kemudian dibandingkan karakteristik fisik dan mekaniknya. Hasil rendemen pati termodifikasi sebesar $90,12 \%$ dengan suhu gelatinasi pati pisang talas yakni $60,41^{\circ} \mathrm{C}$. Dari pengujian karakteristik diperoleh bahwa pati pisang talas pregelatinasi memiliki ukuran partikel yang lebih besar dibandingkan pati pisang talas. Sehingga menyebabkan sifat alir pati pisang talas pregelatinasi lebih baik yakni laju alir sebesar 9,7 g/detik dengan sudut istirahat $23,56^{\circ}$.
\end{abstract}

Kata kunci : Musa paradisiaca var Sapientum L, pati pregelatinasi, eksipien tablet, disintegran 


\section{PENDAHULUAN}

Pati merupakan karbohidrat yang berasal dari hasil proses fotosintesis yang disimpan dalam bagian tertentu tanaman dan berfungsi sebagai cadangan makanan (Soebagio dkk., 2009). Pati dihasilkan oleh tanaman di bagian plastida dan tersimpan di berbagai organ tanaman, seperti umbi (ubi kayu, ubi jalar, kentang, dll), biji (jagung, padi, gandum), batang (sagu) dan buah. Pati memiliki manfaat yang luas salah satunya yaitu dalam bidang industri farmasi. Pati dapat digunakan dalam formulasi sediaan tablet sebagai filler, binder dan disintegrant.

Bahan tambahan (eksipien) yang ada di Indonesia umumnya masih banyak yang diimpor dari Negara lain untuk memenuhi kebutuhan industri farmasi, diantaranya adalah pati yang merupakan eksipien utama dalam sediaan tablet. Indonesia termasuk Negara penghasil pisang terbesar karena 50\% dari produksi pisang Asia dihasilkan oleh Indonesia. Diketahui bahwa pisang mengandung karbohidrat yang cukup tinggi yaitu $70-80 \%$, sehingga buah pisang cukup potensial untuk dikembangkan sebagai sumber pati. Agustin (2013) menemukan bahwa sampel pati pisang talas (Musa paradisiaca var sapientum L) memiliki kapastias penyerapan air dan minyak yang tertinggi dibandingkan kultivar pisang khas Kalimantan lainnya yakni pisang kapas dan pisang mahuli. Sehingga dapat diperkirakan pati pisang talas ideal digunakan sebagai eksipien tablet yaitu disintegrant.

Terdapat dua jenis pati yang sering digunakan dalam industri farmasi yaitu pati yang diolah secara tradisional dan pati modifikasi. Pati yang diolah secara tradisional memiliki kekurangan yakni sifat alir yang buruk sehingga dapat mempengaruhi kompaktibilitas tablet.

Penelitian ini bertujuan untuk memperbaiki kelemahan dari pati tradisional tersebut, sehingga dilakukan modifikasi fisik yakni dengan cara pregelatinasi atau menggunakan teknik pemanasan pati pada suhu gelatinasinya. Setelah diperoleh pati dari proses ekstraksi dan dilakukan modifikasi fisik maka dilakukan evaluasi berupa karakteristik fisik dan mekanik yang kemudian hasilnya dianalisis dan dibandingkan berdasarkan literatur standar pati dan pati pregelatinasi.

\section{METODE PENELITIAN}

\section{Bahan}

Bahan-bahan yang digunakan dalam penelitian ini antara lain sampel buah pisang talas (Musa paradisiaca var sapientum L), aquadest, dan kain saring.

\section{Peralatan}

Peralatan yang digunakan dalam penelitian ini adalah alat-alat kaca $\left(\right.$ Pyrex $\left.^{\circledR}\right)$, timbangan analitik, pisau, blender, oven, penangas air (Stuart ${ }^{\circledR}$ ), termometer, Merlin VR Rheometer (Rheosys ${ }^{\circledR}$ ), ayakan nomor mesh 20, 40, 60, 80, dan 100, gelas objek, mikroskop, mesin penggerak (vibrator), botol timbang, cawan porselen, corong, statif dan klem, stopwatch, dan penggaris. 


\section{Prosedur Pengujian}

\section{Penentuan Suhu Gelatinasi Pati Pisang Talas}

Suspensi pati pisang talas dalam air dibuat dengan konsentrasi $5 \% \mathrm{~b} / \mathrm{v}$ lalu dipanaskan di atas penangas air pada berbagai temperatur yaitu 45, 50, 55, 60, 65 dan $70^{\circ} \mathrm{C}$ selama 5 menit sambil diaduk. Mucilago yang terbentuk ditentukan viskositasnya masing-masing menggunakan viskometer digital. Kemudian dibuat kurva hubungan antara viskositas suspensi terhadap suhu pemanasan. Temperatur gelatinasi merupakan titik potong antara dua garis dengan memakai persamaan garis lurus.

\section{Pembuatan dan Perhitungan Rendemen Pati Pisang Talas Pregelatinasi}

Dibuat suspensi pati pisang talas dalam air dengan konsentrasi $5 \% \mathrm{~b} / \mathrm{v}$ lalu dipanaskan di atas penangas air pada temperatur gelatinasi selama 5 menit. Kemudian didinginkan lalu dikeringkan dalam oven pada temperatur $50^{\circ} \mathrm{C}$, diayak dengan ayakan nomor mesh 80 dan ditimbang beratnya.

\section{Karakteristik Fisik Pati Pisang Talas dan Pati Pisang Talas Pregelatinasi}

\section{Organoleptik}

Pati ditimbang sebanyak 1 gram kemudian diamati menggunakan panca indera yang meliputi bentuk, warna, bau dan rasa.

\section{Mikroskopik}

Ditimbang pati sebanyak $100 \mathrm{mg}$ dan diletakkan pada gelas objek. Selanjutnya ditambahkan 2 tetes aquadest, lalu diamati susunan pati, bentuk hilus dan lamela, serta ukuran granul dari kedua sampel di bawah mikroskop dengan perbesaran 40, 100, 400, dan 1000 kali.

\section{Distribusi ukuran partikel}

Sebanyak 100 gram masing-masing sampel pati dimasukkan ke dalam pengayak dengan nomor 20,40,60, 80, dan 100 mesh yang telah disusun berurutan mulai dari bawah ke atas, dan dipasang pada mesin penggerak (vibrator). Pengayak di atur pada kecepatan $30 \mathrm{rpm}$ selama 20 menit. Serbuk yang tertinggal pada masing-masing ayakan ditimbang dan dihitung masing-masing persentase beratnya.

\section{Kadar air}

Botol timbang dikeringkan pada suhu $105^{\circ} \mathrm{C}$ selama 30 menit dan didinginkan dalam desikator selama 15 menit, lalu ditimbang. Serbuk pati sebanyak 1 gram dimasukkan ke dalam botol timbang tersebut dan ditimbang. Kemudian serbuk dikeringkan pada suhu $105^{\circ} \mathrm{C}$ selama 60 menit, didinginkan dalam desikator selama 15 menit lalu ditimbang kembali. 
Karakteristik Mekanik Pati Pisang Talas dan Pati Pisang Talas Pregelatinasi

Sifat Alir

\section{Laju alir}

Sebanyak 100 gram pati ditimbang. Kemudian pati tersebut dituang melalui tepi corong secara perlahan-lahan ke dalam corong yang bagian bawahnya tertutup. Tutup corong bagian bawah dibuka secara perlahan-lahan dan pati dibiarkan mengalir keluar. Dicatat waktu yang diperlukan (detik) sampai semua pati melewati corong dengan menggunakan stopwatch.

\section{Sudut istirahat}

Sebanyak 100 gram pati ditimbang. Pati tersebut kemudian dituang melalui tepi corong secara perlahan-lahan ke dalam corong yang bagian bawahnya tertutup. Tutup corong bagian bawah dibuka secara perlahan-lahan dan pati dibiarkan mengalir keluar hingga membentuk kerucut. Diukur tinggi pati yang berbentuk kerucut tersebut dan jari-jarinya.

\section{Indeks Kompresibilitas}

Diukur dengan membandingkan hasil kerapatan bulk dan kerapatan mampat. Pengujian kerapatan bulk dilakukan dengan memasukkan pati ke dalam gelas ukur $100 \mathrm{~mL}$ dan ditimbang beratnya. Sedangkan pengujian kerapatan mampat dilakukan dengan proses pengetapan sebanyak 100 kali pada pati yang telah digunakan untuk pengujian kerapatan bulk.

\section{HASIL DAN PEMBAHASAN}

\section{Penentuan Suhu Gelatinisasi Pati Pisang Talas}

Gelatinisasi merupakan proses pengembangan granul pati ketika dipanaskan dalam media air. Apabila granul pati dipanaskan di dalam air, maka energi panas akan menyebabkan ikatan hidrogen terputus, dan air masuk ke dalam granul pati. Air yang masuk akan membentuk ikatan hidrogen dengan amilosa dan amilopektin. Meresapnya air ke dalam granula menyebabkan terjadinya pengembangan granul pati. Ukuran granul akan meningkat sampai batas tertentu sebelum akhirnya granul pati tersebut pecah. Pecahnya granul menyebabkan bagian amilosa dan amilopektin berdifusi keluar. 


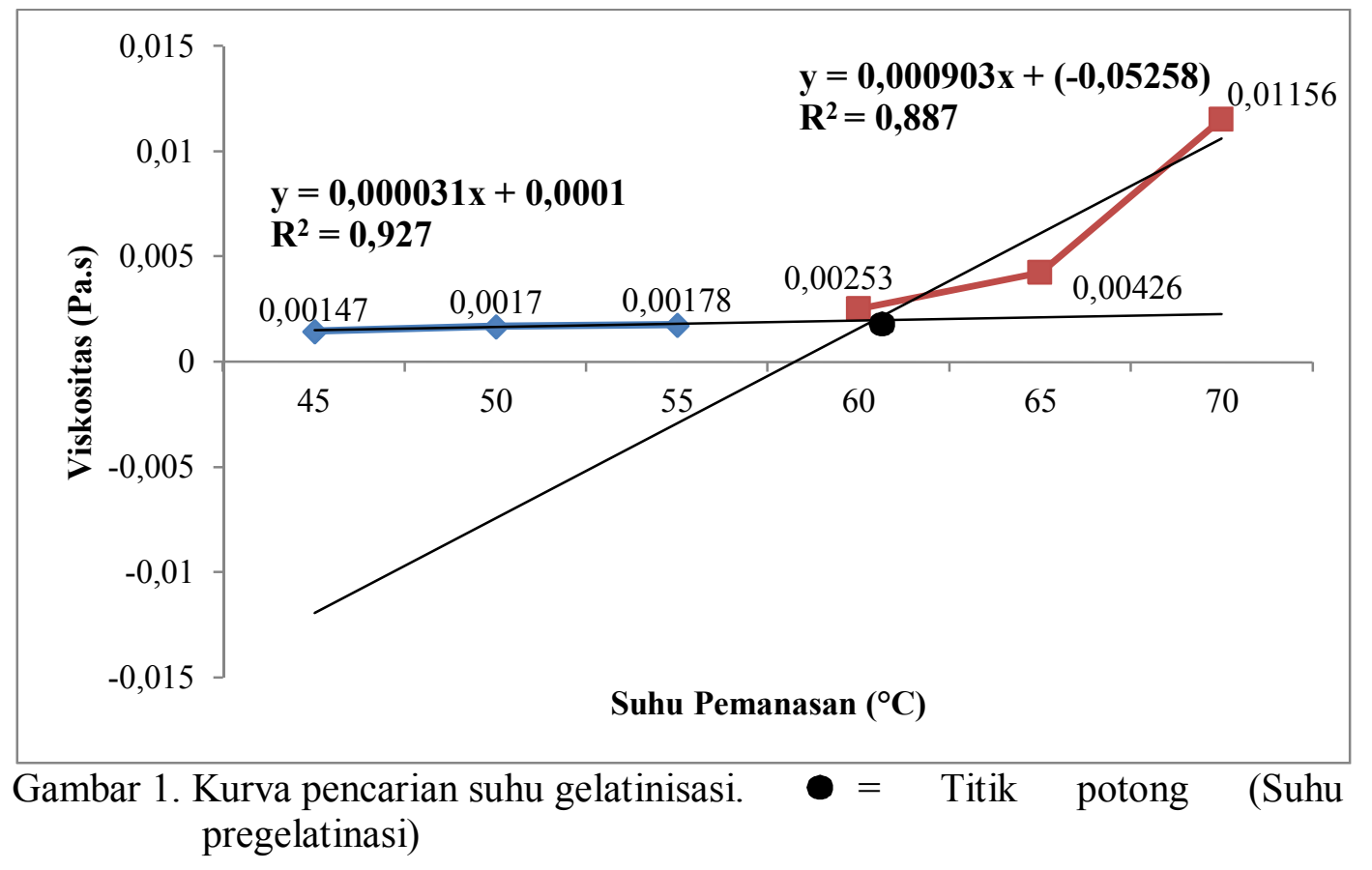

Berdasarkan hasil pengukuran viskositas pada sampel pati pisang talas dengan berbagai suhu pemanasan, maka diperoleh suhu gelatinisasi pati pisang talas yakni $60,41^{\circ} \mathrm{C}$. Nilai ini diperoleh dari titik potong antara dua garis menggunakan persamaan garis lurus. Pada kurva ini pula dapat terlihat bahwa pati yang dipanaskan menggunakan suhu $60^{\circ} \mathrm{C}$ menunjukkan tercapainya suhu awal gelatinisasi, karena viskositas cairan meningkat lebih pesat dibandingkan viskositas cairan pati yang dipanaskan pada suhu 45,50 , dan $55^{\circ} \mathrm{C}$. Peningkatan viskositas ini dikarenakan terjadinya pengembangan granula pati yang bersifat irreversible di dalam air.

\section{Pembuatan dan Perhitungan Rendemen Pati Pisang Talas Pregelatinasi}

Suhu gelatinisasi yang telah diperoleh kemudian digunakan untuk melakukan modifikasi fisik pati pisang talas pregelatinasi dengan cara memanaskan suspensi pati pisang talas pada suhu 60 hingga $61^{\circ} \mathrm{C}$ selama 5 menit, kemudian didinginkan dan dikeringkan dalam oven pada temperatur $50^{\circ} \mathrm{C}$. Pati yang telah kering diayak dan ditimbang. Hasil rendemen pati pisang talas pregelatinasi yakni sebesar $90,12 \%$.

\section{Karakteristik Fisik Pati Pisang Talas dan Pati Pisang Talas Pregelatinasi}

\section{a. Organoleptik}

Uji ini dilakukan dengan tujuan untuk memastikan sampel yang digunakan atau diperoleh dari proses ekstraksi adalah pati diamati dari ciri-ciri fisiknya, serta mengamati perbedaan yang terjadi setelah pati tersebut dimodifikasi. 
Tabel 1. Hasil uji organoleptik

\begin{tabular}{ccc}
\hline \multirow{2}{*}{ Parameter } & \multicolumn{2}{c}{ Sampel } \\
\cline { 2 - 3 } & Pati pisang talas & Pati pisang talas pregelatinasi \\
\hline Warna & Putih kecoklatan & Putih kecoklatan \\
Bau & Tidak berbau & Tidak berbau \\
Bentuk & Serbuk halus & Serbuk halus \\
Rasa & Tidak berasa & Tidak berasa \\
\hline
\end{tabular}

Berdasarkan tabel 1. menunjukan bahwa sampel terbukti merupakan pati ditinjau dari ciri-ciri fisiknya sesuai dengan literatur Handbook of pharmaceutical excipients edisi VI yang menuliskan bahwa pada umumnya pati memiliki ciri-ciri yakni berwarna putih hingga putih gelap, tidak berbau, tidak berasa dan berbentuk serbuk (Rowe et al, 2009).

\section{b. Mikroskopik}

Uji mikroskopik ini dilakukan untuk mengetahui susunan pati, bentuk hilus dan lamela, serta ukuran granula pati karena bentuk granula pati spesifik untuk setiap jenis pati sehingga dapat dibedakan antara satu dengan yang lainnya.

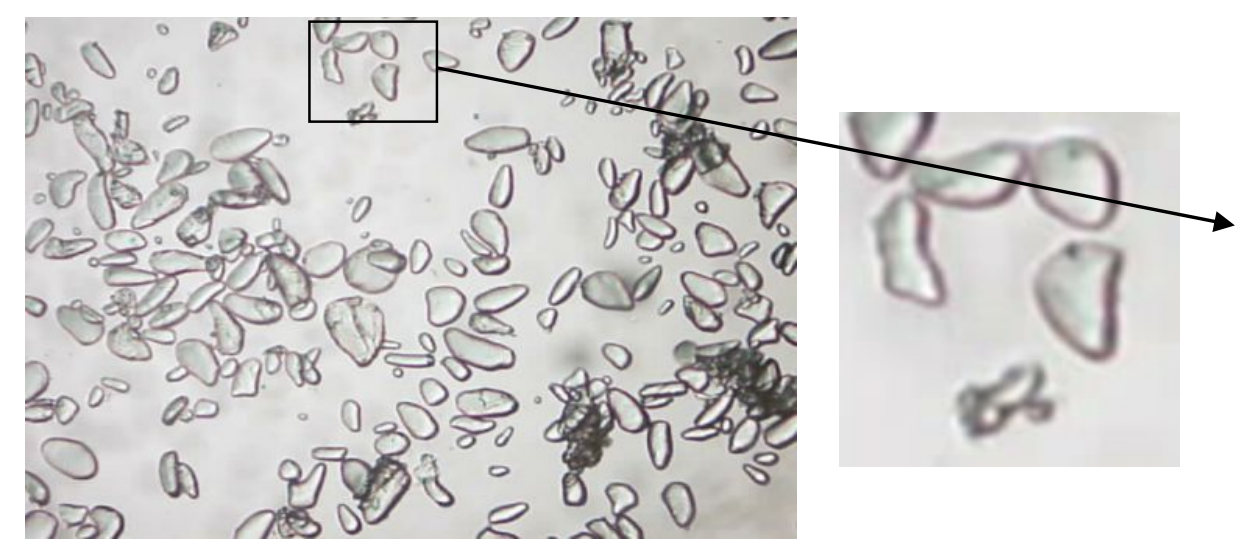

Gambar 2. Hasil uji mikroskopik pati pisang talas

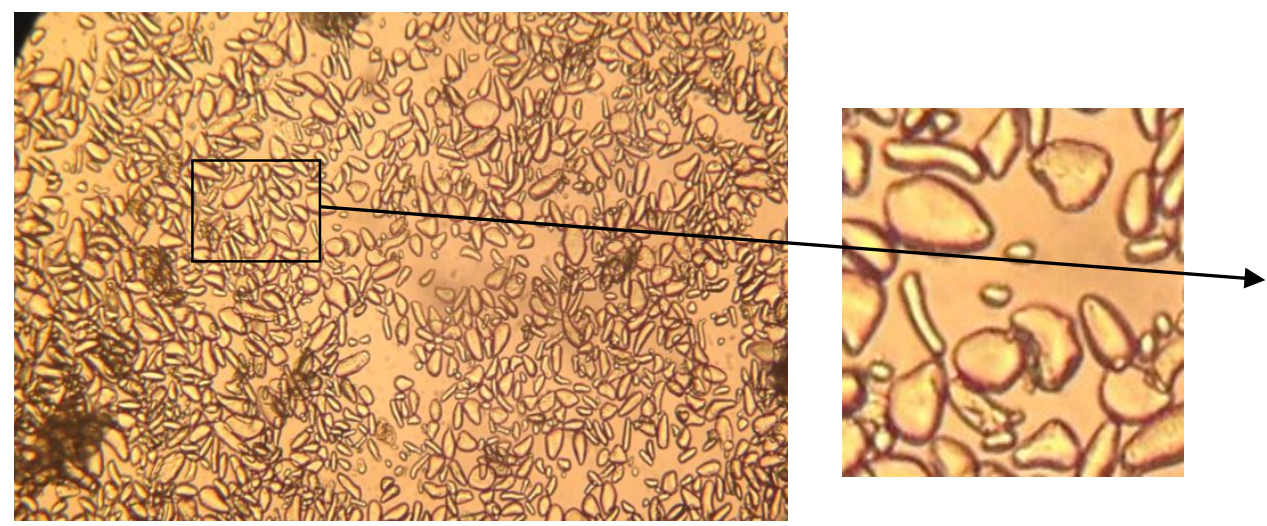

Prosiding Seminar Nasional Kefarmasian Ke-1 
Gambar 3. Hasil uji mikroskopik pati pisang talas pregelatinasi

Gambar 2 dan 3 merupakan pengamatan menggunakan mikroskop pada perbesaran 100 kali yang menunjukkan bahwa pati pisang talas sebelum dimodifikasi memiliki bentuk granul oval, dengan lamela terlihat dan memiliki hilus yang terletak di ujung. Sedangkan pati pisang talas pregelatinasi menunjukkan bahwa pati ini memiliki bentuk serupa dengan pati pisang talas sebelum dimodifikasi yakni oval, hanya saja pati pregelatinasi memliki ukuran granul yang lebih besar. Pati pisang talas memiliki ukuran granul $26 \mu \mathrm{m}$ dan granul pati pisang talas pregelatinasi berukuran $29 \mu \mathrm{m}$. Perubahan ukuran ini disebabkan karena proses gelatinisasi yang terjadi. Proses gelatinisasi mengakibatkan granul-granul pati membengkak dan berubah menjadi susunan yang bergerombol (Kurniadi, 2010).

\section{c. Distribusi ukuran partikel}

Tabel 2. Uji Distribusi Ukuran Partikel

\begin{tabular}{|c|c|c|c|c|}
\hline \multirow[b]{2}{*}{$\begin{array}{c}\text { Mesh } \\
\text { Ayakan }\end{array}$} & \multicolumn{2}{|c|}{ Pati Pisang Talas } & \multicolumn{2}{|c|}{ Pati Pisang Talas Pregelatinasi } \\
\hline & $\begin{array}{l}\text { Berat Tertahan } \\
(\mathrm{g})\end{array}$ & $\begin{array}{c}\text { Bobot serbuk } \\
(\%)\end{array}$ & $\begin{array}{l}\text { Berat Tertahan } \\
(\mathrm{g})\end{array}$ & $\begin{array}{c}\text { Bobot serbuk } \\
(\%)\end{array}$ \\
\hline & 84,5615 & 84,46 & 75,1104 & 75,04 \\
\hline$<125 \mu \mathrm{m}$ & & & & \\
\hline $100 \mathrm{Mesh}$ & 2,7949 & 2,79 & 5,4648 & 5,46 \\
\hline $125-150 \mu \mathrm{m}$ & & & & \\
\hline 80 Mesh & 4,7303 & 4,72 & 7,0302 & 7,02 \\
\hline $151-180 \mu \mathrm{m}$ & & & & \\
\hline $\begin{array}{c}60 \mathrm{Mesh} \\
181-250 \mathrm{um}\end{array}$ & 7,9628 & 7,95 & 12,1909 & 12,18 \\
\hline $40 \mathrm{Mesh}$ & 0,0639 & 0,06 & 0,2428 & 0,24 \\
\hline $251-425 \mu \mathrm{m}$ & & & & \\
\hline $\begin{array}{c}20 \text { Mesh } \\
426-850 \mu \mathrm{m}\end{array}$ & 0,0062 & 0,006 & 0,0593 & 0,06 \\
\hline
\end{tabular}

Berdasarkan Tabel 2. dapat terlihat bahwa ukuran partikel serbuk pati pisang talas sebelum dan setelah dimodifikasi terdistribusi dalam berbagai ukuran, sebagian besar berukuran $<150 \mu \mathrm{m}$. Ukuran partikel dapat mempengaruhi kemampuan laju alir suatu serbuk. Semakin halus ukuran partikel maka laju alir akan berkurang. Hal ini disebabkan karena daya kohesivitas antarpartikel semakin besar. Laju alir suatu serbuk sangat mempengaruhi keseragaman bobot tablet yang akan dihasilkan.

Terlihat pula bahwa persentase bobot serbuk berukuran $<150 \mu \mathrm{m}$ pada pati pisang talas sebelum di modifikasi lebih besar dibandingkan persentase bobot serbuk pati pisang talas pregelatinasi. Hal ini menunjukkan bahwa pati pisang talas 
pregelatinasi mengalami perubahan ukuran partikel menjadi lebih besar karena pada saat proses gelatinisasi terjadi pengembangan granul pati akibat adanya air dan pemanasan yang mengakibatkan ukuran granul pati setelah dimodifikasi menjadi lebih besar.

\section{d. Kadar air}

Hasil yang diperoleh yaitu kadar air pada pati pisang talas sebelum dimodifikasi sebesar $6,03 \%$ sedangkan pati pisang talas pregelatinasi sebesar $6,61 \%$. Perbedaan ini dapat dikarenakan pati pisang talas pregelatinasi yang telah melalui proses kontak dengan air dan pemanasan sehingga ukuran partikel pati membesar dan menyebabkan kemampuan menyerap air yang besar pula. Apabila dikeringkan membutuhkan waktu yang lebih lama dibandingkan pati pisang talas tanpa modifikasi karena adanya air yang masih terikat pada granula pati. Pada umumnya, berbagai jenis pati mengandung air 10-20\% (Swinkles, 1985). Berdasarkan Farmakope Indonesia Edisi IV, kadar air tidak boleh lebih dari 15\%. Hasil pengujian kandungan air kedua sampel pati pisang talas memenuhi kriteria pati yang ideal.

\section{Karakteristik Mekanik Pati Pisang Talas dan Pati Pisang Talas Pregelatinasi}

\section{a. Sifat alir}

1. Laju alir

Tabel 3. Hasil pengujan laju alir

\begin{tabular}{lcccc}
\hline \multirow{2}{*}{ Sampel } & \multicolumn{3}{c}{ Laju alir (g/t) } & $\begin{array}{c}\text { Rata-rata } \\
\text { Laju alir (g/t) }\end{array}$ \\
\cline { 2 - 4 } & Replikasi 1 & Replikasi 2 & Replikasi 3 & - \\
Pati pisang talas & - & - & - & 9,7 \\
$\begin{array}{l}\text { Pati pisang talas } \\
\text { pregelatinasi }\end{array}$ & 9,10 & 10,00 & 10,00 & \\
\hline
\end{tabular}

Berdasarkan tabel 3. terlihat bahwa pati pisang talas sebelum dimodifikasi tidak memiliki data laju alir, dikarenakan pati pisang talas tidak mampu mengalir sama sekali untuk melewati corong. Sedangkan pati pisang talas pregelatinasi memiliki laju alir rata-rata sebesar 9,7 g/detik. Kriteria serbuk memiliki laju alir yang ideal yakni lebih dari $10 \mathrm{~g} /$ detik (Aulton, 2002).

Maka dapat ditentukan bahwa pati pisang talas pregelatinasi memiliki laju alir yang lebih baik karena mendekati kriteria persyaratan laju alir yang ideal dibandingkan pati pisang talas sebelum dimodifikasi. Faktor yang mempengaruhi perubahan laju alir yaitu ukuran partikel serbuk (Martin, 1993). Ukuran partikel yang halus akan membatasi kemampuan serbuk untuk mengalir dengan bebas karena adanya gaya lekat antar partikel dengan gaya gravitasi. Ukuran partikel serbuk pati pisang talas sebelum dimodifikasi lebih kecil dibandingkan pati pisang 
talas pregelatinasi sehingga menyebabkan laju alir pati pisang talas sebelum dimodifikasi lebih buruk dibandingkan laju alir pati pisang talas pregelatinasi.

\section{Sudut istirahat}

Metode sudut istirahat telah digunakan sebagai metode tidak langsung untuk mengukur mampu alir granul karena hubungannya dengan kohesi antarpartikel. Hasil pengujian sudut istirahat sampel pati pisang talas dan pati pisang talas pregelatinasi dapat dilihat pada tabel 4 dan 5.

Tabel 4. Hasil uji sudut istirahat pati pisang talas

\begin{tabular}{cccccc}
\hline Replikasi & $\begin{array}{c}\text { Diameter } \\
(\mathrm{cm})\end{array}$ & $\begin{array}{c}\text { Jari-jari } \\
(\mathrm{cm})\end{array}$ & $\begin{array}{c}\text { Tinggi } \\
(\mathrm{cm})\end{array}$ & $\begin{array}{c}\tan \\
\alpha(\mathrm{h} / \mathrm{r})\end{array}$ & $\alpha\left(^{\circ}\right)$ \\
\hline 1 & 18,2 & 9,1 & 4,4 & 0,57 & 29,68 \\
2 & 17,5 & 8,75 & 4 & 0,46 & 24,70 \\
3 & 17 & 8,5 & 4,2 & 0,49 & 26,10 \\
\hline \multicolumn{5}{c}{ Rata-rata } \\
\hline
\end{tabular}

Tabel 5. Hasil uji sudut istirahat pati pisang talas pregelatinasi

\begin{tabular}{cccccc}
\hline Replikasi & $\begin{array}{c}\text { Diameter } \\
(\mathrm{cm})\end{array}$ & $\begin{array}{c}\text { Jari-jari } \\
(\mathrm{cm})\end{array}$ & $\begin{array}{c}\text { Tinggi } \\
(\mathrm{cm})\end{array}$ & $\begin{array}{c}\tan \\
\alpha(\mathrm{h} / \mathrm{r})\end{array}$ & $\alpha\left(^{\circ}\right)$ \\
\hline 1 & 17,6 & 8,8 & 3,5 & 0,40 & 21,80 \\
2 & 16,8 & 8,4 & 3,5 & 0,42 & 22,78 \\
3 & 15,9 & 7,95 & 3,9 & 0,49 & 26,10 \\
\hline \multicolumn{5}{c}{ Rata-rata } \\
\hline
\end{tabular}

Dari Tabel 4 dan 5 dapat dilihat bahwa sudut istirahat yang dimiliki oleh pati pisang talas sebelum dimodifikasi yakni sebesar $26,83^{\circ}$ sedangkan pati pisang talas pregelatinasi memiliki sudut istirahat sebesar $23,56^{\circ}$. Nilai sudut istirahat sampai dengan $40^{\circ}$ menunjukkan serbuk memiliki laju alir yang baik sedangkan jika nilai sudut istirahat lebih dari $50^{\circ}$ maka serbuk memiliki laju alir yang buruk. Semakin kecil nilai sudut istirahat maka semakin baik pula laju alirnya. Suatu granul yang tidak kohesif akan mengalir dengan baik, menyebar dan membentuk timbunan yang rendah. Semakin datar kerucut yang dihasilkan artinya sudut kemiringan semakin kecil sehingga akan semakin baik daya alir serbuk tersebut (Voigt, 1995).

\section{b. Indeks kompresibilitas}

Uji indeks kompresibilitas merupakan suatu parameter yang menandakan kemampuan suatu bahan untuk digunakan dengan metode cetak langsung pada proses pembuatan tablet. Indeks kompresibilitas suatu eksipien berhubungan erat 
dengan ukuran partikel dan distribusinya. Hasil pengujian indeks kompresibilitas dapat dilihat pada tabel 6 dan 7.

Tabel 6. Hasil pengujian indeks kompresibilitas pati pisang talas

\begin{tabular}{cccc}
\hline Replikasi & $\begin{array}{c}\text { Kerapatan bulk } \\
(\rho \mathrm{B})(\mathrm{g} / \mathrm{mL})\end{array}$ & $\begin{array}{c}\text { Kerapatan mampat } \\
(\rho)(\mathrm{g} / \mathrm{mL})\end{array}$ & Indeks kompresibilitas \\
\hline 1 & 0,46 & 0,72 & \multirow{2}{*}{$36,98 \%$} \\
2 & 0,46 & 0,74 & \\
3 & 0,46 & 0,74 & \\
\hline Rata-rata & 0,46 & 0,73 & \\
\hline
\end{tabular}

Tabel 7. Hasil pengujian indeks kompresibilitas pati pisang talas pregelatinasi

\begin{tabular}{cccc}
\hline Replikasi & $\begin{array}{c}\text { Kerapatan bulk } \\
(\rho \mathrm{B})(\mathrm{g} / \mathrm{mL})\end{array}$ & $\begin{array}{c}\text { Kerapatan mampat } \\
(\rho)(\mathrm{g} / \mathrm{mL})\end{array}$ & Indeks kompresibilitas \\
\hline 1 & 0,51 & 0,75 & \\
2 & 0,51 & 0,75 & $32 \%$ \\
3 & 0,51 & 0,75 & \\
\hline Rata-rata & 0,51 & 0,75 & \\
\hline
\end{tabular}

Berdasarkan tabel 6 dan 7 menunjukkan bahwa pati pisang talas sebelum dimodifikasi memiliki nilai indeks kompresibilitas sebesar 36,98\% dan pati pisang talas pregelatinasi memiliki nilai indeks kompresibiltas sebesar 32\%. Aulton (2002) menuliskan bahwa indeks kompresibilitas kurang dari 18\% umumnya memberikan sifat alir yang baik, namun nilai indeks kompresibilitas 18-23\% masih diperbolehkan karena dalam rentang kategori cukup mengalir sedangkan indeks kompresibilitas lebih dari 38\% menunjukkan kemampuan alir yang buruk.

Hasil tersebut menunjukkan bahwa pati pisang talas pregelatinasi memiliki nilai indeks kompresibilitas yang lebih baik dibandingkan pati pisang talas sebelum dimodifikasi. Hal ini dikarenakan bentuk ukuran partikel pati pisang talas pregelatinasi yang lebih besar ditinjau dari hasil pengujian mikroskopik dan distribusi ukuran partikel. Ukuran partikel granul yang lebih besar memudahkan partikel untuk mengalir sehingga menghasilkan sifat alir yang baik pula.

\section{KESIMPULAN}

1. Suhu gelatinisasi pati pisang talas sebesar $60,41^{\circ} \mathrm{C}$

2. Rendemen pati pisang talas pregelatinasi sebesar $90,12 \%$

3. Perbedaan karakteristik pati pisang talas dan pati pisang talas pregelatinasi yakni ukuran partikel pati pisang talas pregelatinasi lebih besar sehingga menghasilkan sifat alir pati yang lebih baik dibandingkan pati pisang talas sebelum dimodifikasi 


\section{UCAPAN TERIMA KASIH}

Penulis menyampaikan ucapan terimakasih kepada Dekan Fakultas Farmasi Universitas Mulawarman dan Kepala Laboratorium Penelitian dan Pengembangan FARMAKA TROPIS Fakultas Farmasi atas izin melaksanakan penelitian.

\section{DAFTAR PUSTAKA}

[1] Agustin, Sukmiyati dan Rohmah, Miftakhur. 2013. Karakterisasi Sifat Fisikokimia dan Fungsional Tepung dan Pati dari Tiga Kultivar Pisang (Musa spp.) Khas Kalimantan Timur. Fakultas Pertanian Universitas Mulawarman: Samarinda.

[2] Aulton, M. E. 2002. Pharmaceutics The Science of Dosage Form Design. Churcill Livingstone: New York.

[3] Departemen Kesehatan Republik Indonesia. 1995. Farmakope Indonesia, Edisi ke empat. Departemen Kesehatan RI: Jakarta.

[4] Kurniadi, T. 2010. Kopolimerasi Grafiting Monomer Asam Aklirat pada Onggok Singkong dan Karakteristiknya. Institut Pertanian Bogor: Bogor.

[5] Martin, A., Swarbick, J., \& Cammarata, A. 1993. Farmasi Fisik Dasar-Dasar Kimia Fisik Dalam Ilmu Farmasetik (Yoshita, Penerjemah). UI Press: Jakarta.

[6] Rowe, R.C., Sheskey, P.J., and Quinn, M.E. 2009. Handbook of Pharmacetical excipients $6^{\text {th }}$ edition. The Pharmaceutical Press: London.

[7] Soebagio, B., Sriwododo, Adhika, A. S. 2009. Pengujian Sifat Fisikokimia Pati Biji Durian (Durio Zibethinus Murr) Alami dan Modifikasi cecara Hidrolisis Asam. Universitas Padjadjaran: Bandung.

[8] Swinkles J.J.M. 1985. Source of Starch, Its Chemistry and Physics. dalam: Starch Conversion Technology. G.M.A Van Beynum and J.A Roles. New York: Marcel Dekker Inc 15-46

[9] Voigt, R. 1995. Buku Pelajaran Teknologi Farmasi (Soendani Noerono Soewandhi dan Mathilda B. Widianto, penerjemah). Gadjah Mada University Press: Yogyakarta. 